\title{
Does Fasting during Ramadan Alter Body Composition, Blood Constituents and Physical Performance?
}

\author{
J. Ramadan \\ Department of Physiology, Faculty of Medicine, Kuwait University, Kuwait
}

\author{
Key Words \\ Ramadan fasting . Heart rate - Oxygen consumption . \\ Blood pressure $\cdot$ Exercise $\cdot$ Body composition
}

\begin{abstract}
Objective: To study the effect of Ramadan fast (RF) on body composition, plasma constituents, hematology, and cardiorespiratory responses to constant submaximal exercise. Subjects and Methods: Sixteen sedentary healthy Kuwaiti adult males were included in the study. The subjects were tested under thermo-neutral conditions during a spring-like month of Ramadan and 2 months thereafter. They were tested during the week before RF (Prel); the last 3 days of RF (End1); the week before a non-Ramadan month (Pre2), and the last 3 days of the non-Ramadan month (End2). The following measurements were made: body composition, cellular and biochemical constituents of blood, heart rate, ventilatory responses and blood pressure. Results: No significant changes were observed in body composition, cellular and biochemical constituents of blood. The heart rate and ventilatory responses to the moderately intense bouts of submaximal aerobic exercise $\left(-70 \%\right.$ of $\left.\mathrm{VO}_{2 \max }\right)$ were significantly reduced $(p<0.04)$ while systolic blood pressure increased $(p<0.05)$ by the end of RF. Conclusions: Ramadan fasting had no adverse effect on the subjects when performing aerobic exercise at submaximal
\end{abstract}

level. The mild changes in cardiorespiratory responses could be due to dehydration, abstention from consumption of substances with negative inotropy and circadian rhythms.

Copyright $\odot 2002$ S. Karger AG, Basel

\section{Introduction}

Ramadan is the holy month in Islam during which time millions of adult Muslims abstain from intake of food and drink from sunrise to sunset. Ramadan month advances 11 days each year and, therefore, can occur during any season of the year and consequently the effects of the daytime fasting are strongly influenced by climatic conditions, being most severe during the summer [1]. Daily living routines during Ramadan are markedly altered. The alterations affect the duration, intensity and types of ritual commitments, eating schedules, the amount and types of food consumed, the volume and timing of fluid ingestion, the duration and intensity of physical activity, working hours, recreational activities, and the sleeping patterns.

The aim of the present study was to investigate changes in body composition, cellular and biochemical constituents of the blood, and cardiorespiratory responses to moderately heavy aerobic physical performance during the fasting month of Ramadan.

\begin{tabular}{ll}
\hline KARGER & ( ) 2002 S. Karger AG, Basel \\
$1011-7571 / 02 / 0116-0041 \$ 18.50 / 0$ \\
$\begin{array}{l}\text { Fax +41613061234 } \\
\begin{array}{l}\text { E-Mail karger@karger.ch } \\
\text { www.karger.com }\end{array}\end{array}$ & $\begin{array}{l}\text { Accessible online at: } \\
\text { www.karger.com } / \mathrm{mpp}\end{array}$
\end{tabular}

Dr. Jasem Ramadan
Department of Physiology
Faculty of Medicine, Kuwait University
PO Box 24923, 13110 Safat (Kuwait)
Tel. +965 5319593, Fax +965 5338937, E-Mail ramadan@hsc.kuniv.edu.kw 
Table 1. Anthropometric measurements during Ramadan and non-Ramadan periods

\begin{tabular}{|c|c|c|c|c|}
\hline \multirow[t]{2}{*}{ Parameter } & \multicolumn{2}{|c|}{ Ramadan month } & \multicolumn{2}{|c|}{ Non-Ramadan month } \\
\hline & Pre1 & End1 & Pre2 & End2 \\
\hline Weight, kg & $80.16 \pm 2.7$ & $79.1 \pm 2.8$ & $79.6 \pm 2.8$ & $79.5 \pm 2.9$ \\
\hline Skinfolds, mm & $67.6 \pm 5.4$ & $67.4 \pm 5.6$ & $65.6 \pm 5.3$ & $66.1 \pm 5.5$ \\
\hline FFM & $60.7 \pm 1.3$ & $60.3 \pm 1.2$ & $62.7 \pm 1.8$ & $62.1 \pm 1.8$ \\
\hline
\end{tabular}

Values are mean \pm SE of 16 subjects. FFM $=$ Fat free mass.
Table 2. Cardiorespiratory and metabolic responses to maximal and submaximal exercise during Ramadan and non-Ramadan periods

\begin{tabular}{|c|c|c|c|c|}
\hline \multirow[t]{2}{*}{ Parameter } & \multicolumn{2}{|l|}{ Ramadan } & \multicolumn{2}{|c|}{ Non-Ramadan } \\
\hline & Pre1 & End1 & Pre2 & End2 \\
\hline $\mathrm{VO}_{2}$ submax, $1 / \min$ & $2.4 \pm 0.1$ & $2.3 \pm 0.1$ & $2.32 \pm 0.12$ & $2.3 \pm 0.12$ \\
\hline $\mathrm{VO}_{2}$ submax, $\%$ of $\max$ & $72.2 \pm 2.3$ & $70.9 \pm 3.0$ & $70.9 \pm 2.5$ & $69.6 \pm 2.6$ \\
\hline $\mathrm{V}_{\mathrm{E}}$ submax, $1 / \min$ & $64.3 \pm 3.6$ & $61.0 \pm 3.9$ & $64.0 \pm 3.7$ & $64.3 \pm 3.7$ \\
\hline R submax & $0.94 \pm 0.01$ & $0.93 \pm 0.02$ & $0.95 \pm 0.02$ & $0.97 \pm 0.01$ \\
\hline DP submax, mm Hg & $86.7 \pm 1.8$ & $87.0 \pm 1.6$ & $84.1 \pm 1.8$ & $83.4 \pm 1.18$ \\
\hline $\mathrm{DP}$ rest, $\mathrm{mm} \mathrm{Hg}$ & $83.9 \pm 1.3$ & $80.3 \pm 1.4$ & $82.4 \pm 1.3$ & $82.3 \pm 1.5$ \\
\hline
\end{tabular}

Values are mean $\pm 1 \mathrm{SE}$ of 16 subjects. $\mathrm{DP}=$ Diastolic pressure; $\mathrm{VO}_{2}=$ oxygen uptake; $\mathrm{HR}=$ heart rate $\mathrm{V}_{\mathrm{E}}=$ respiratory ventilation; $\mathrm{R}=$ respiratory exchange ratio.

\section{Subjects and Methods}

Subjects. Sixteen sedentary adult Kuwaiti male volunteers participated in the study. The subjects did not participate regularly in recreational or health-related physical programs. Informed consent was obtained from each subject and each volunteer could withdraw from the study at any time.

Body Composition. Body weight was measured to an accuracy of $0.1 \mathrm{~kg}$, using Detecto Scales (Detecto Scales Inc., New York, N.Y., USA). Estimation of body density (BD) was obtained by using the skinfold technique. A Harpenden skinfold caliper (John Bull, British Indictors Ltd, UK) was used to measure the adipose layer on the dominant side of the body surface at three sites: chest, abdomen, and thigh. Calculation of BD was made according to Jackson and Pollock's equation [2]. The percentage of body fat was predicated using the age-specific equation of Siri [3]; tests on a sample of men and women showed an error of $1-3 \%$, relative to more direct estimates by underwater weighing [4]. Body fat weight (FWT) was calculated by multiplying the percentage of fat by total body weight (TBW). Fat free body weight (FFWT) was obtained according to the following formula: FFWT = TBW - FWT.

Maximal and Submaximal Exercise. To determine the level of submaximal exercise, each volunteer underwent a maximal progressive graded treadmill test during the week before the start of Ramadan fast (RF) and the week before the non-Ramadan month. The moderately heavy submaximal aerobic treadmill exercise (at $\sim 70 \%$ of $\mathrm{VO}_{2 \max }$ ) were performed (a) during the week before RF (Pre1); (b) the last 3 days of RF (End1); (c) the week before non-Ramadan month (Pre2) and (d) the last 3 days of non-Ramadan month (End2). For the Ramadan and non-Ramadan months, the tests were performed in January and April, respectively. The tests were conducted in a thermo-neutral laboratory environment where temperature $\left(25^{\circ} \mathrm{C}\right)$ and relative humidity $(30 \%)$ were kept constant throughout the study period. The exercise tests were performed on a Quinton Y65 treadmill (Quinton, Bothell, Wash., USA) according to the progressive Bruce protocol [5]. Heart rate and ECG recordings were monitored using Quinton Q 5000 at rest and during exercise. Oxygen uptake $\left(\mathrm{VO}_{2}\right)$ and carbon dioxide produced was measured using a Quinton Q-plex 1. Calculations were computerized and results plotted on line. For submaximal exercise, the work rate was kept constant and monitored throughout the test.

Blood Analysis. Two venous blood samples (5 and $10 \mathrm{ml})$ were collected in EDTA and plain tubes for routine hematology (Backman Coulter Ltd., Bucks., UK), and blood chemistry analyses (Boehringer Mannheim Automated Analyzer, BM/Hitachi System 717, Mannheim, Germany).

Data Analysis. To eliminate interindividual variability in responses and to compare each subject's responses at the same absolute exercise load, the data for each subject were normalized to the values observed during the first test in each period. Data were analyzed using SPSS Statistical Package.

Data are presented as means \pm 1 SEM. Differences between the means were considered significant when a significant ANOVA of a pair or unpaired two-tailed t-test had a $\mathrm{p}<0.05$. 


\section{Results}

The average age and height were $35.0 \pm 1.9$ years and $171.3 \pm 1.7 \mathrm{~cm}$, respectively. The weight, skinfolds, and fat free mass (FFM) are summarized in table 1. Average body weight of the subjects did not change significantly during Ramadan (fig. 1A, B). Skinfold measurements of subcutaneous body fat did not reveal any significant change in body composition during the month of Ramadan (table 1). During the 4-week non-Ramadan testing period, the same subjects also did not show any significant change in body weight nor in subcutaneous body fat folds (table 1). The lack of significant change in body weight and subcutaneous body fat folds indicates that food intake from sunset to sunrise was sufficient to maintain energy balance in spite of the daytime RFs.

During the maximal graded exercise tests the $\mathrm{VO}_{2 \max }$ $(3.3 \pm 0.2 \mathrm{l} / \mathrm{min})$ showed that the subjects were on average moderately fit for their age group and that the aerobic fitness level (aerobic capacity $40.5 \pm 1.6 \mathrm{ml} / \mathrm{min} \cdot \mathrm{kg}^{-1}$ ) (the best objective measure of their physical work capacity) did not change significantly during the month of Ramadan (table 2). The maximal heart rates $\left(\mathrm{HR}_{\max }\right)$ exceeded the predicted $\mathrm{HR}_{\max }$ for their age group $\left(\mathrm{HR}_{\max }=187 \pm 3 \mathrm{bpm}\right)$, and the respiratory exchange ratio $(\mathrm{R})$ exceeded 1.1 in all subjects (table 2 ).

The average percentage of the steady-state submaximal exercise loads used during the tests were approximately $72 \%$ of $\mathrm{VO}_{2 \max }(2.31 / \mathrm{min})$. The average percentage of aerobic effort decreased insignificantly during the month of Ramadan (to $70.9 \%$ at 4 weeks, $\mathrm{p}<0.5$ ) and did not show any significant change during the similar nonRamadan 4-week testing period for the same subjects (table 2). The speed and percent grade used during the submaximal exercise tests, although variable from subject to subject, remained constant for each subject in all tests performed during and after Ramadan.

The steady-state systolic pressure observed at similar submaximal exercise loads, increased progressively during the month of Ramadan; the increase reached statistical significance by the fourth week of Ramadan (fig. 2A, B). During the non-Ramadan testing period of the same subjects, the submaximal exercise systolic pressure did not increase significantly at the fourth week test (fig. 2A, B). Diastolic pressure during exercise, systolic and diastolic pressure at rest, did not change during or after Ramadan (table 2).

The average heart rate response to the submaximal aerobic exercise loads decreased progressively and significantly by the fourth week of Ramadan (fig. 3A, B), but
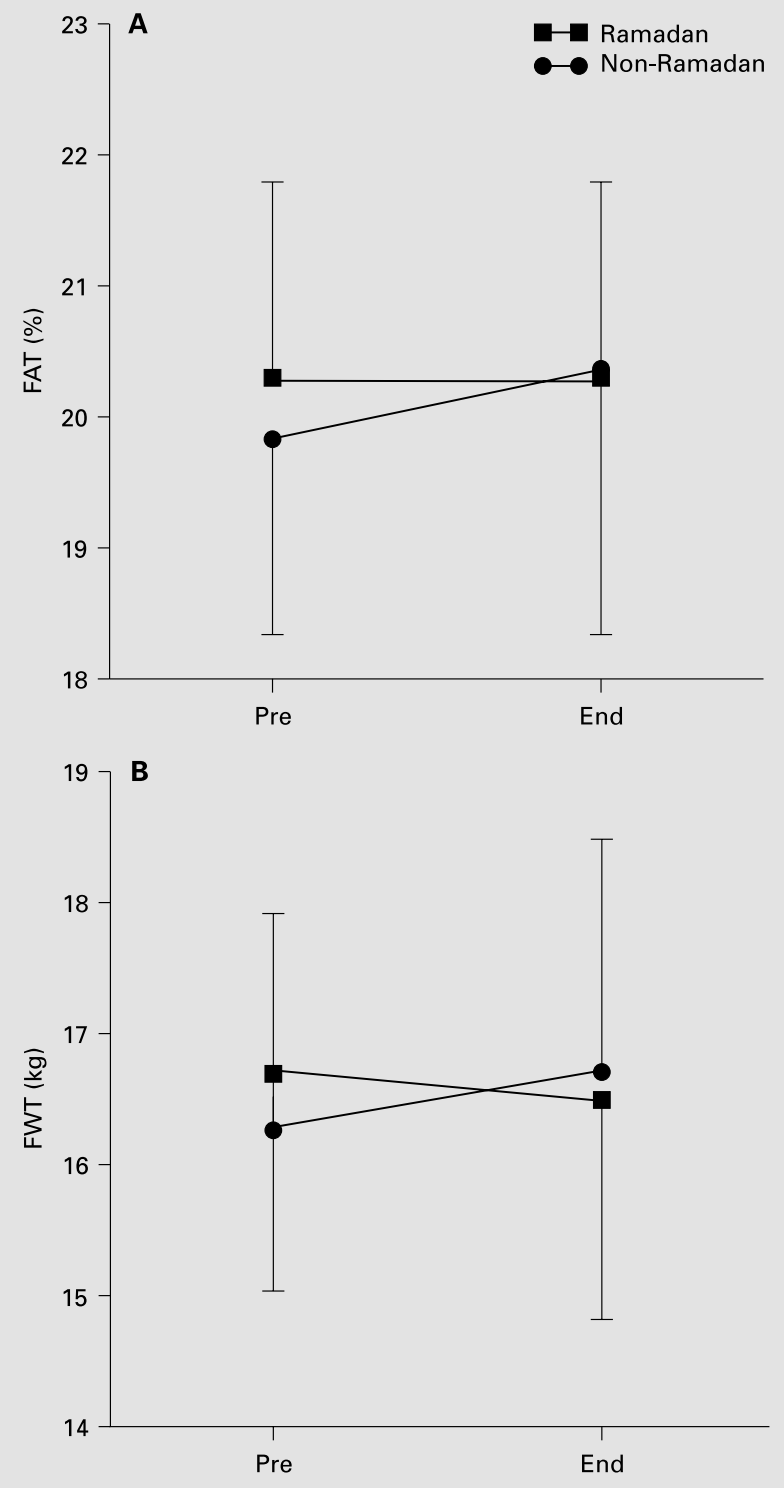

Fig. 1. Percentage of fat (A) and fat weight (B) during Ramadan and non-Ramadan testing periods.

showed no significant change at the corresponding fourth week of the non-Ramadan testing period (fig. 3A, B).

The respiratory ventilation $\left(\mathrm{V}_{\mathrm{E}}\right)$ during the bouts of submaximal aerobic exercise decreased from an average of 64.3 to $61 \mathrm{l} / \mathrm{min}$ during the month of Ramadan (table 2). Analysis showed that the small change (5.3 \pm $2.4 \%$ ) that occurred in each subject from week 0 to week 4 was statistically significant $(\mathrm{p}<0.05)$, thereby indicating 

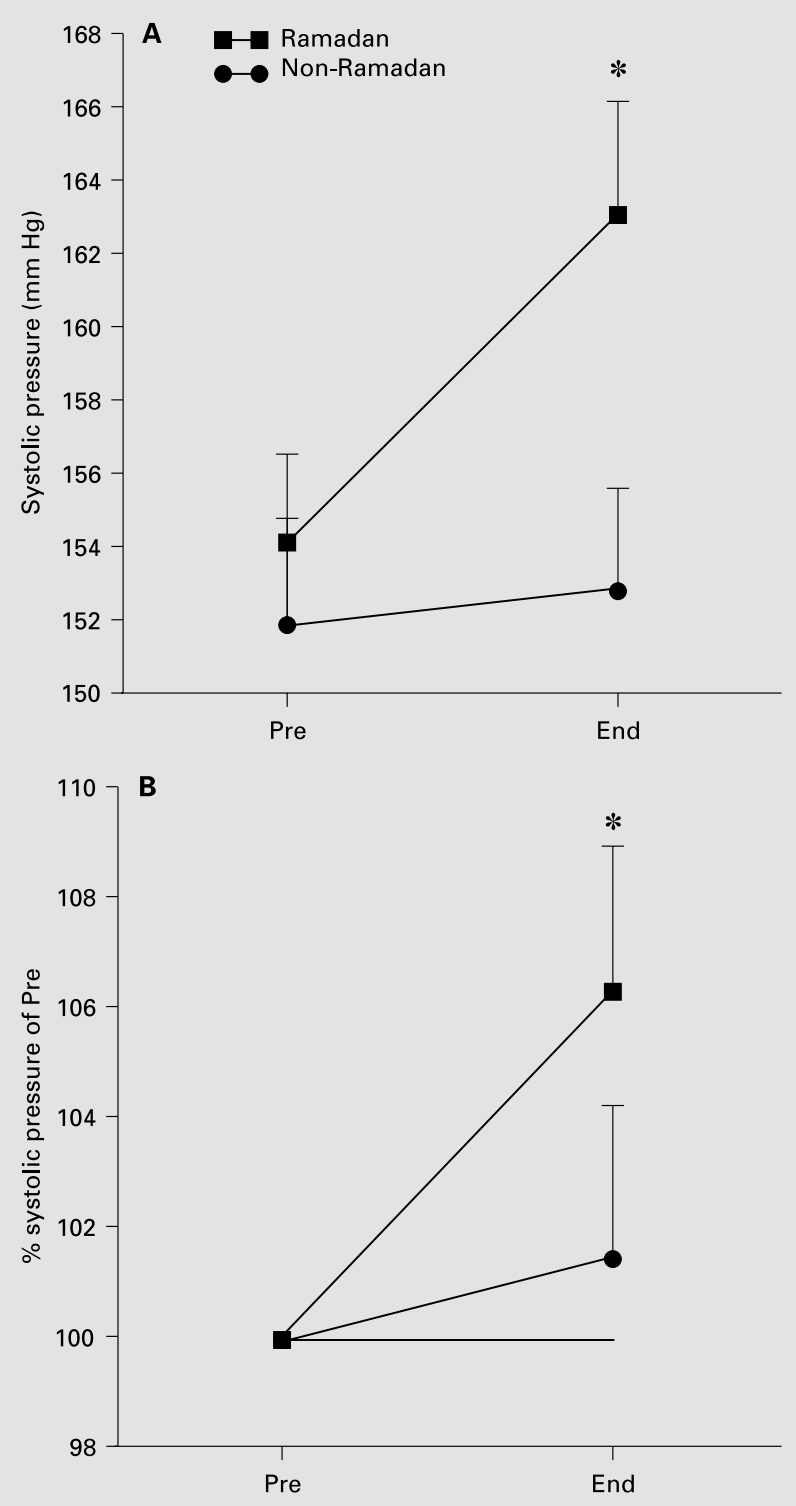

Fig. 2. A Submaximal exercise systolic blood pressure ( $\mathrm{mm} \mathrm{Hg}$ ) during Ramadan and non-Ramadan testing periods. B Submaximal exercise systolic blood pressure (\% of control) during Ramadan and non-Ramadan testing periods.

that the decrease in exercise $\mathrm{V}_{\mathrm{E}}$ during Ramadan was consistent in all subjects. However, $\mathrm{V}_{\mathrm{E}}$ during similar submaximal exercise loads did not change significantly during the 4-week non-Ramadan testing period (table 2). The respiratory exchange ratio $(\mathrm{R})$ during the submaximal exercise loads did not significantly change during the Ramadan or the non-Ramadan testing periods (table 2).
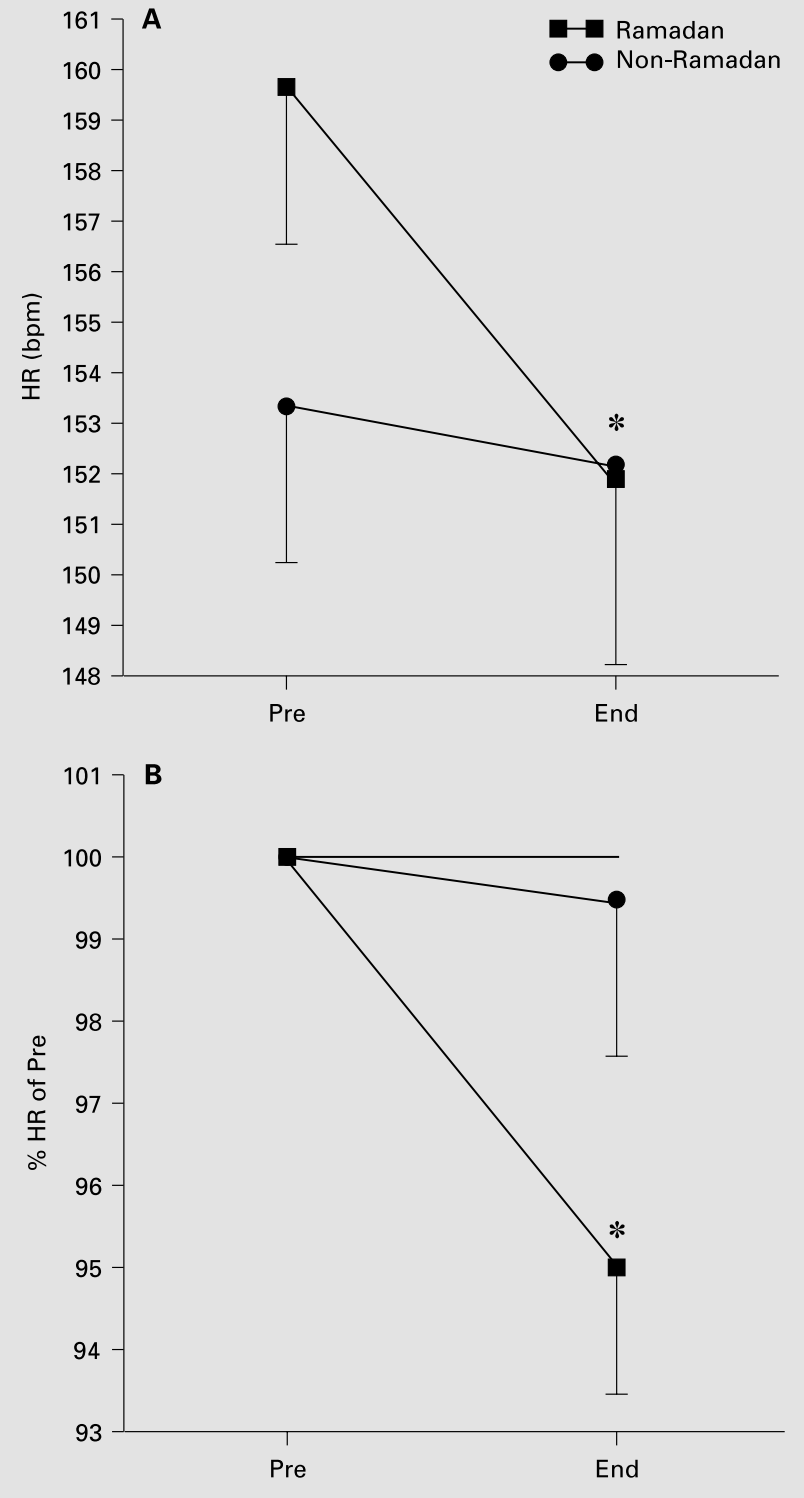

Fig. 3. A Submaximal exercise heart rates (bpm) during Ramadan and non-Ramadan testing periods. B Submaximal exercise heart rates ( $\%$ of control) during Ramadan and non-Ramadan testing periods.

The hematocrit, blood hemoglobin concentration, red and white blood cell counts were unchanged during both Ramadan and non-Ramadan testing periods (table 3 ). Also, no change was detected in plasma constituents during testing periods (table 4). 
Table 3. Blood hematology before and at the end of the Ramadan month

\begin{tabular}{lcc}
\hline Constituents & \multicolumn{2}{c}{$\begin{array}{l}\text { Hematological constituents } \\
\text { for Ramadan month }\end{array}$} \\
\cline { 2 - 3 } & Pre & End \\
\hline Hematocrit ratio & $46.6 \pm 1.0$ & $45.7 \pm 1.0$ \\
Hemoglobin, g/dl & $16.1 \pm 0.4$ & $15.8 \pm 0.4$ \\
Platelets, $10^{9} / 1$ & $230.5 \pm 10.1$ & $218.8 \pm 12.0$ \\
Red blood cell count,$\times 10^{12} / 1$ & $5.5 \pm 0.2$ & $5.5 \pm 0.5$ \\
White blood cell count,$\times 10^{9} / 1$ & $6.1 \pm 0.5$ & $5.8 \pm 0.4$
\end{tabular}

Values are mean \pm SE of 16 subjects.

Table 4. Serum and plasma chemical constituents before and at the end of the Ramadan month

\begin{tabular}{lrr}
\hline Constituents & \multicolumn{2}{c}{$\begin{array}{c}\text { Plasma constituents } \\
\text { for Ramadan month }\end{array}$} \\
\cline { 2 - 3 } & \multicolumn{2}{c}{ Pre End } \\
\hline Chloride, $\mathrm{mmol} / \mathrm{l}$ & $106.6 \pm 0.5$ & $108.78 \pm 0.9$ \\
Glucose, $\mathrm{mmol} / \mathrm{l}$ & $5.0 \pm 0.1$ & $5.5 \pm 0.1$ \\
Albumin, $\mathrm{g} / \mathrm{l}$ & $44.5 \pm 0.8$ & $45.1 \pm 0.8$ \\
Cholesterol, $\mathrm{mmol} / \mathrm{l}$ & $5.0 \pm 0.2$ & $5.1 \pm 0.1$ \\
Total protein, $\mathrm{g} / \mathrm{l}$ & $70.2 \pm 0.8$ & $70.8 \pm 0.6$ \\
Iron, $\mu$ mol $/ \mathrm{l}$ & $17.7 \pm 1.2$ & $14.6 \pm 0.9$ \\
Triglycerides, $\mathrm{mmol} / \mathrm{l}$ & $1.4 \pm 0.2$ & $1.3 \pm 0.1$ \\
Creatinine, $\mu \mathrm{mol} / \mathrm{l}$ & $86.9 \pm 2.3$ & $88.2 \pm 2.4$ \\
\end{tabular}

Values are mean \pm SE of 16 subjects.

\section{Discussion}

There were no significant changes in maximal exercise capacity, percentage of $\mathrm{VO}_{2 \max }$, treadmill walking efficiency, body weight and body composition (skinfolds) associated with Ramadan fasting.

The observed changes, reductions in heart rate and ventilation and an increase in systolic but not in diastolic blood pressure in cardiorespiratory responses to submaximal exercise during the month of Ramadan were small but significant. The slight reduction in ventilatory response that was detected by the fourth week of Ramadan may reflect a lower acid stimulus to ventilation secondary to reduced production of lactic acid by muscles where the glycogen reserves may be low [6], thereby limiting the anaerobic process by the end of Ramadan.
The significant increase in systolic pressure without corresponding change in resting diastolic blood pressure and aerobic fitness level that occurred within a short period of time during the submaximal exercise could be due to changes in arterial elasticity. Thus the increase in systolic pressure could represent an increase in pulse pressure due to a large stroke volume. An increase in stroke volume during exercise may be secondary to a positive inotropic effect of hormones such as angiotensin II [7] and glucagon [8], which increase in plasma concentration during dehydration [9] and fasting [10]. Alternatively it may be secondary to increases in central blood volume due to redistribution of blood from the periphery to central reservoirs [11] during the prolonged period of consecutive daytime abstentions from fluids, salt and other foods. Hormonal changes (e.g. glucagon) with consequence on cardiac chrono- and inotropism may also result from the changes in eating, activity, sleep and circadian patterns that occur during the months of Ramadan. It is also possible that substance(s) that were avoided during Ramadan (such as cigarettes) have a negative inotropic influence.

The decrease in heart rate may be due to reduction in the intensity of the effort during the submaximal exercise. However, there were no significant changes in $\mathrm{VO}_{2 \max }$ or in the percentage of $\mathrm{VO}_{2 \max }$ during the submaximal exercise bouts either during the Ramadan or the non-Ramadan testing period. The speed and grade at which the subjects walked were the same throughout both testing periods. The efficiency of walking on the treadmill was unchanged during the tests and therefore the familiarity of the subjects with walking on the treadmill was not a factor that accounted for the decrease in exercise heart rate. Hence the observed lower heart rate during Ramadan may be interpreted to reflect an improvement in the physical condition of the subjects rather than any deleterious effect of the RF. However, it occurred independent of the initial physical condition and of the habitual level of physical activity of the subjects as previously described [12]. It is therefore not due to a 'training' effect.

We cannot discard possible cardiac effects of avoiding certain substances (such as cigarettes) or of volume regulatory hormones such as antidiuretic hormone [13], which increase in concentration in the plasma as a consequence of the dehydration that progressively develops during the RF [13]. This dehydration becomes more severe as the month of Ramadan progresses, as indicated by increases in the urine and the plasma osmolarities [14], as well as by increases in plasma sodium [14] and in plasma chloride (table 4) concentrations. 
The present study indicated that the direction and magnitude of the observed changes in cardiorespiratory responses to exercise is such that they should have no negative impact on, and may rather be of benefit to, the ability to perform aerobically either at work or recreationally, at least when the Ramadan fasts occur in a relatively neutral thermal environment. Such changes are likely to be different and more severe when the month of Ramadan occurs during the summer and more extreme warm temperatures and humidity or both are present. The cardiovascular responses to exercise may be particularly altered during peregrinations when exposure to heat, long periods of immobility, crowding and increases in physical activity will reinforce the effects of deprivation of fluids, salt and food. Reduced ventilation during heavy exercise by the end of Ramadan may reflect a limited glycolytic capacity that may interfere with anaerobic efforts.

The responses of these sedentary subjects to moderately intense bouts of submaximal aerobic exercise are not markedly affected by the daytime fasts that occur during the month of Ramadan. There are no significant changes in maximal exercise capacity, in body composition, nor in the efficiency of treadmill walking at a defined grade and speed during the Ramadan testing period. We have previously shown that there are no differences in the physiological responses to moderate submaximal aerobic exercise between sedentary and physically active subjects and thus that no training effects are involved $[11,14]$.

\section{Conclusion}

In general, Ramadan fasting did not produce a detrimental effect on performing physical activity, and on the energy balance of the individual.

\section{Acknowledgments}

The author thanks Prof. M. Barac-Nieto for his valuable comments, Mr. G. Telahoun and A. Hammouda for their assistance in preparing the manuscript, and Mrs. M. Varghese for typing the manuscript.

\section{References}

1 Husain R, Duncan MT, Cheah SH, Ch'ng SL: Effects of fasting in Ramadan on tropical Asiatic Moslems. Br J Nutr 1987;58:41.

2 Jackson S, Pollock ML: Generalised equations for predicting body density in man. Br J Nutr 1978;40:497-504.

3 Siri WE: Body composition from fluid spaces and density: Analysis of methods; in Brozek J, Henschel A (eds): Techniques for Measuring Body Compositions. Washington, National Academy of Science, 1961, p 233.

4 Wilmore KM, McBride PJ, Wilmore JH: Comparison of bioelectric impedance and nearinfrared interaction for body composition assessment in a population of self-perceived overweight adults. Int J Obes 1994; 18:375-381
5 Bruce RL, Kusumi F, Hosmer D: Maximal oxygen intake and nomographic assessment of functional aerobic impairment in cardiovascular disease. Am Heart J 1973;85:545-562.

6 Heyndrickx GR, Boettcher DH, Vanter SF: Effects of angiotensin, vasopressin, and methoxamine on cardiac function and blood flow distribution in conscious dogs. Am J Physiol 1976;231:1579-1589.

7 Farah AK: Glucagon and the circulation. Pharmacol Rev 1983;35:181-217.

8 Laragh JH, Baer L, Brunner HR: Renin angiotensin and aldosterone system in pathogenesis and management of hypertensive vascular disease. Am J Med 1972;52:633-652.

9 Cahill GF, Herrera MG, Morgan AP, Soeldner JS: Hormone fuel interrelationships during fasting. J Clin Invest 1966;45:1751-1769.

10 Wilcox CS, Puritz R, Lightm SL: Plasma volume regulation in patients with progressive autonomic failure during changes in salt intake or posture. J Lab Clin Med 1984;104:331-339.
11 Ramadan J, Mousa M, Telahoun G: Effect of Ramadan fasting on physical performance, blood and body composition. Med Principles Pract 1994;95:204-212.

12 Walker BR, Childs ME, Adams EM: Direct cardiac effects of vasopressin: Role of V1- and V2-vasopressinergic receptor. Am J Physiol 1988;255:H261-H265.

13 Mustafa KY, Mahmoud NA, Gumaa KA, Gader AMA: The effects of fasting in Ramadan. Fluid and electrolyte balance. Br J Nutr 1978; 40:83-89.

14 Jasem R, Telahoun G, Al-Zaid NS, Barac-Nieto $\mathrm{M}$ : Responses to exercise, fluid and energy balance during Ramadan in sedentary and active males. Nutrition 1999;15:735-739. 